\title{
Analysis on News Images of the Tokyo Olympic Games Athletes in Chinese Sina Weibo from the Perspective of the Male Gaze
}

\author{
Yushi Luo ${ }^{1, *}$ \\ ${ }^{1}$ Department of Journalism, College of Journalism and Communication, Jinan University, Guangdong, Guangzhou \\ 510000, China. \\ ${ }^{*}$ Corresponding author. Email: LouiseLuo2021@163.com
}

\begin{abstract}
The male gaze is a high-profile and crucial research topic in visual culture field. However, few studies pay attention to Chinese sports context and authoritative media. This research applied the male gaze theory to analyse the frame in news images of Chinese athletes of the Tokyo Olympic Games on Chinese social media Sina Weibo. It took the athletes images from official Weibo account of the People's Daily as samples and discussed dimensions of facial expression and gesture, clothing and photographic angle as well as position in the frame. Result shows that the male gaze mainly manifests as replacement in females' powerful appearance, decoration and sex implication in clothing and photographic angle and inferior position and invisibility in the frame. They satisfied men's desire of control, possession and superior to women, and are resulted from combination of conventional Chinese ideology and western consumerism. The article implicated the male gaze in news images of athletes in China and extended the existing theory to the news reports and Chinese social media context, as well as enriched research subjects of the male gaze.
\end{abstract}

Keywords: News image, Athlete, Chinese Sina Weibo, The male gaze, The People's Daily.

\section{INTRODUCTION}

Sports is a traditional field of male power, and existing research reveal that the gender discrimination and male gaze is widespread in sports. However, it is noticed that professional comprehensive medias, not only the sports media, also show a tendency of male gaze.

Male gaze has become a significant theme in social science since 1970s. Laura Mulvey reveals the male gaze in cinema and describes how "women are simultaneously looked at and displayed, with their appearance coded for a strong visual and erotic impact so that they can be said to connote to-be-looked-at-ness" [1] . Most of the time, male gaze is connected with cameras and images. Pang finds femininity can be fixed in portable and framed images to be circulated within the largely patriarchal popular culture in the photography[2]. The sight of camera means the desire of the eyes behind the lens, as well as the desire of the audiences. Male gaze continues to exist as the erotic basis for pleasure in looking at other persons as objects[1]. Sontag also discovers the nature of photography is a potent means of acquiring and gaining control over it. In the male gaze, the image of female is controlled, constructed, produced and consumed by themale, while the determining male gaze projects its fantasy onto the female figure[3].

Apart from the cinema, sports is another field controlled by male gaze. Along the history, sports is one of the best way for men to display their masculinity. Thus when women take part in this field in modern times, they suffer enormous discrimination. Gaze is a crucial feature of public sporting experience, and many female athletes images offer sensual, sexualized female body for the appraising male eye[4]. When the attention of audiences focuses on the athletes' or even reporters' body, male gaze and desire are produced. Cummins et al. find that a greater ratio of time on female reporters' bodies to their faces relative to male reporters[5]. Merrill et al. reveal that the blogs constructs an atmosphere that exposes attitudes of objectification, perceives lack of credibility, and the sexual economy of sports blogs[6]. Girls feel pressure from male gaze to present their bodies to boys as passively beautiful or to be competent at sport[7]. Gieseler puts her attention on 
how females resist the male gaze in skating[8]. Another fact is that, sports medias also guide the sight of audiences to the female body. The male gaze has pervasive effects on media content, objectification occurs when the media emphasize female bodies or body parts collectively[6]. Meanwhile, the clothing of female displayed by the media also has influence, when show provocatively attired the women are objectified[9].

Most of the research on the male gaze in sports and sports media bases on the context of western world, and the male gaze they focus on are mainly popular or commercial. Studies on Chinese sports context and authoritative media are still absent. This research applied the male gaze theory to analyse the frame in news images of Chinese athletes of the Tokyo Olympic Games posted by the People's Daily on the popular Chinese social media Weibo. It extended the existing theory to the news reports and Chinese social media context and applied it to new materials of the Olympic Games images. The article discussed male gaze through dimensions of facial expression and gesture, clothing and photographic angle as well as position in the frame.

\section{METHODS}

The research used qualitative study methods, which was text analysis. Researcher collected samples from the official Sina Weibo account of the People's Daily. Two photos of different genders were grouped together in order to display more clearly. There were also screenshots of the whole Weibo message to show the arrangement of images. Then the study compared and analysed the expression, post, gesture, costume, position and other aspects of athletes images of different genders from the perspective of the male gaze.

\section{RESULT AND DISCUSSION}

\subsection{The replaced power of female athletes}

In the Tokyo Olympic Games, female athlete Zhang Yufei won the 13th gold medal for China in the women's 200-meter butterfly stroke, and the next day, male athlete Wang Shun won the 16th gold medal of China in the men's 200-meter medley stroke. The People's Daily sent a Weibo message for each athlete when they won the champion, and edited a collection of all the champion images so far irregularly. Figure1 is the Weibo congratulated Zhang Yufei for her gold medal and figure 2 is a part of the images collection which included both Zhang Yufei and Wang Shun. We can find that the photo of Zhang Yufei was changed in the images collection.

In the photo of the single-person Weibo, Zhang Yufei was swimming is the lane of the competition. She was breathing heavily and the facial expression was distorted.
Muscle definition of her arms appeared significantly, and the swimming goggles and cap as well as the water in the pool covered up her female characteristics. It is hard to distinct gender of the person in the photo at first glance. Zhang Yufei showed her power and sthenia in this high-impact photo " just like a man".

However, in figure 2 she was transformed into a woman. She took off the swimming goggles and exposed her eyes, with a big warm smile on her face. She watched the camera and lifted her arms to express her joy. Features and expression clearly indicated that she is a woman. Meanwhile, the image of Wang Shun in figure 2 is very similar to the image of Zhang Yufei in figure 1 , in the gesture, the facial expression, the muscle definition, the location and the frame.

When the audiences have eye contact with Zhang Yufei in figure 2, they may feel a connection and closeness. They think they are observing Zhang Yufei when watching figure1 but communicating with her when watching figure 2 . The fact is that they are gazing at and obtaining her. Mulvey described eye contact as a way of male gaze,

"each is associated with a look: that of the spectator in direct scopophilic contact with the female form displayed for his enjoyment (connoting male fantasy) and that of the spectator fascinated with the image of his like set in an illusion of natural space, and through him gaining control and possession of the woman within the diegesis"[10].

Pang also regarded looking at the camera as a manifestation of the female subject being captured and manipulated by photography. She thought a girl's refusal to look at the camera highlight a sense of self-awareness[2]. Therefore, Zhang's image in figure 2 and her reaction to the camera is a kind of obedience, "the woman sees herself being seen, and she partly directs her own objectification"[11].

The closeness audiences feel from the image, is a kind of feminity constructed by the photographer and the news editor, in order to settle her in the field controlled by males. "Women are deprived of the distance required by language, femininity is closeness, nearness, 'wrapped in its own contiguity'... These discourses assign to the woman a position, a place within a patriarchal culture. [12]" By contrast, figure 2 shows a strong and masculine male athlete as well as a modest and feminine female athlete.

The essence of the replacement of image between two figures is the avoidance and identity of setoff of female in front of the male. The authoritative press were willing to express a female's power and capacity when she appears alone. Nevertheless, she has to regress to a submissive and effeminate position and abandon her possession of being strong and powerful when she 


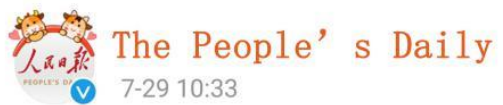

The 13th gold medal! Zhang Yufei of China won the women's $200 \mathrm{~m}$ butterfly final at the Tokyo 0lympic Games, while Yu Liyan of China placed sixth.

Congratulations @o Zhang Yufei o, congratulations @Yu $1-\mathrm{Y}-$ !

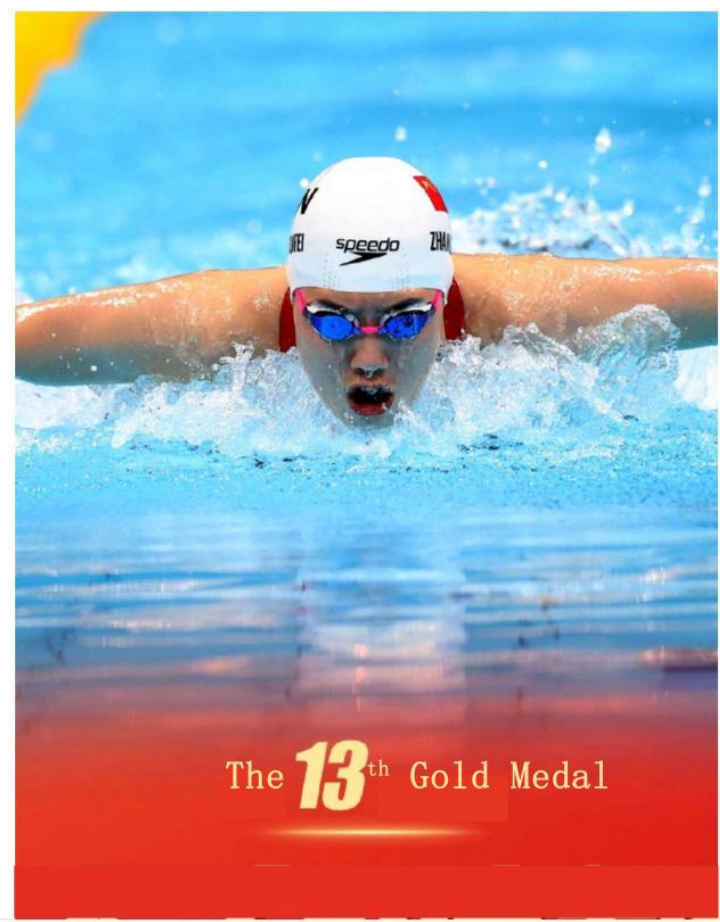

Figure 1 the news report on Zhang Yufei by the People's Daily(The writing is: The $13^{\text {th }}$ gold medal! Zhang Yufei of China won the women's 200m butterfly final at the Tokyo Olympic Games, while Yu Liyan of China placed sixth. Congratulations @o Zhang Yufei o, congratulations@Yu l-Y -!)
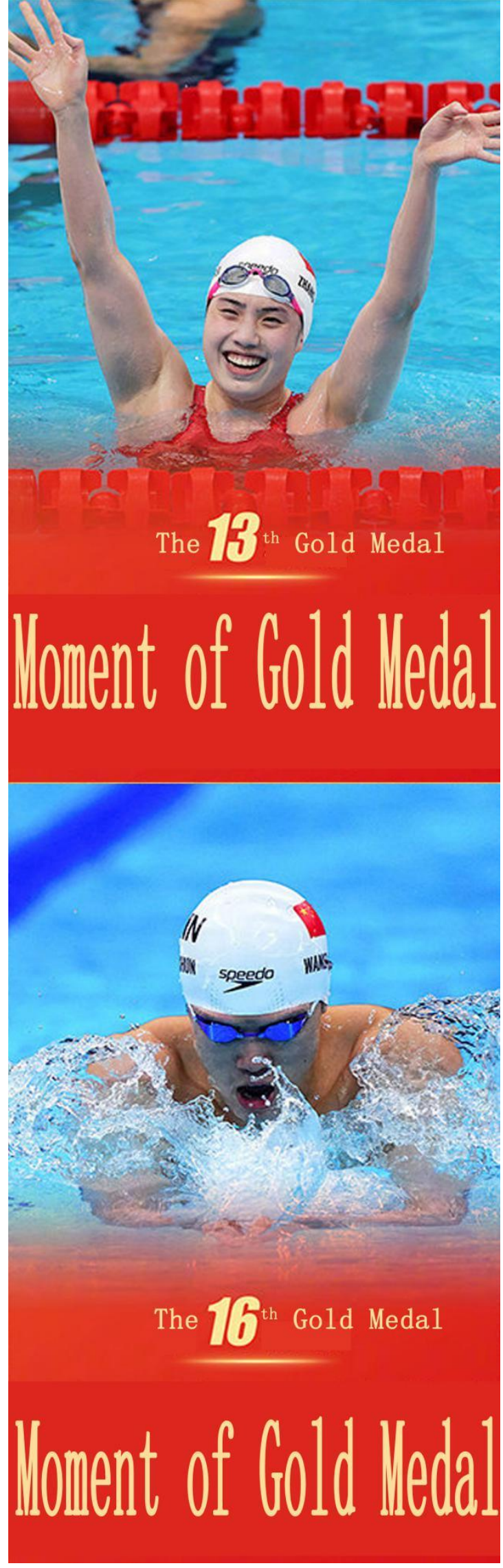

Figure 2 the collection images of champions of the Tokyo Olympic Games by the People's Daily (Zhang Yufei upper and Wang Shun below) 
stands with a man, because being strong and powerful is thought to be the exclusive strength of the male. That's a way media castrate female and emphasis male.

\subsection{Decoration, bareness and possession}

Clothing is one of the most attractive part in a portrait photography, and in many situation clothing covers a large proportion of the frame. In other hand, clothing plays a significant role in the Olympic Games. Governments invite designers to design clothing for their athletes, even for diverse competition items in order to represent the identity of their nations. A widespread phenomenon is that, the clothing of female athletes are usually different from the male athletes, even in the same item and with same elements.

Figure 3 shows two Chinese gymnast images of Tokyo Olympic Games. The upper one is Tang Qianjing, a female athlete who won the silver medal of balance beam, and the below one is Xiao Ruoteng, a male athlete who won the silver medal of Gymnastics men's individual all-around. It can be seen that Tang Qianjing is wearing a skintight clothing fitting her body well and highlighting the outline of her body, especially in her haunch. The bottom clothing is designed in the style of briefs which completely bares the legs of the female athletes, and the top of this clothing is like a tight T-shirt with half sleeves. Perhaps some of the audiences are confused when they see this clothing, because it seems

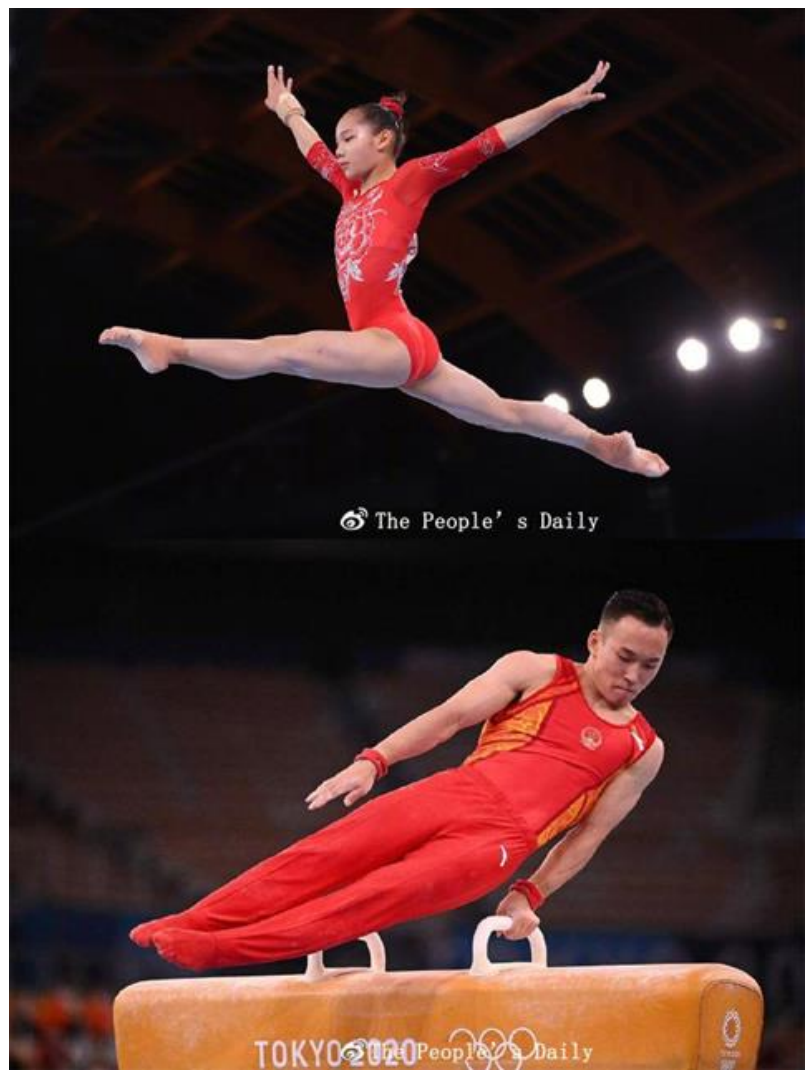

Figure 3 Chinese gymnastics athletes Tang Qianjing (upper) and Xiao Ruoteng (below) to be consisted of two separate parts, a controversial top half part and an erogenous bottom half part. Besides, Tang Qianjing's clothing is well-decorated. Big flowers made of silver spangles appear in the chest and back, making the female athlete dazzling. On the contrary, Xiao Ruoteng's clothing is of another style. It is made of cotton and more loose, particularly the trousers. The design of vest emphasizes the muscle of his arms. Although this clothing is also red, the material and decorated color lump make it matt and low-key.

Some people may argue that athletes in figure 3 are not exactly in the same item, so let us have another example. Figure 4 shows the Chinese women's and men's $4 \times 100$ meters teams, and we can clearly find that their clothing are totally different. A short vest and a briefs comprise a female's clothing, uncovering her waist, abdomen and legs, while a male's clothing is a jumpsuit like the combination of T-shirt and shorts. These two teams are in the same item, with same competition rules and methods, however their clothing diverse.

Therefore, what actually influences the design of clothing is gender rather than item or other requests. In the mind of the designer, authority and ruling class, the images of female should be polychrome, ornamental, fascinating and distinct in their body line, so they place more color, pattern and decoration on the clothing and make it fit. This not only happens in China, but happens

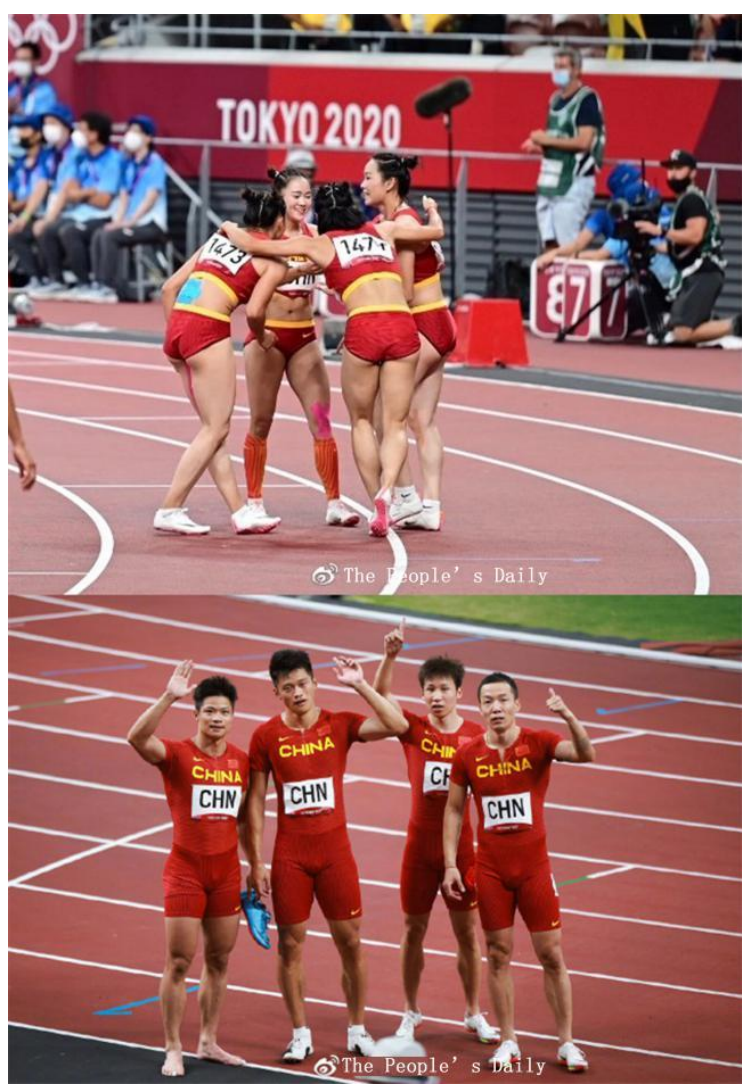

Figure 4 Chinese women's (upper) and men's (below) $4 \times 100$ meters teams 
almost in every country. And if the females want to resist the manipulation of their body, they will be suppressed and punished. A recent example is the Norwegian women's beach handball team were fined by the disciplinary committee at the 2021 European Beach Handball Tournament for "inappropriate attire" because they refused to compete in bikini bottoms.

Pang indicates that in the $19^{\text {th }}$ and early $20^{\text {th }}$ century of China, courtesan fashion was a material link between the consumers and consumed. The courtesans put on flashy clothing and decorations to attract the attention of rich men, while the rich men gave them money and the incentive to buy the clothing, with the ultimate aim of showing off not just the courtesans but themselves as patrons[2]. At that time, courtesans were the main force to be photoed and communicated, thus they bore the task of becoming exhibitions. However nowadays such task is distributed to every woman, especially female celebrities. They are encouraged and forced to decorate and bare their bodies, and satisfied the males' possession unconsciously.

What display female along with the clothing is the photographic angle. The focus on Tang's legs and genitals is a kind of the 'worm's eye view', which contributes to wards representing the female body in a highly erotic and sexualised way, by amplifying the wide positioning of the legs and the vector that converges on the genital area[13].

Combination of clothing and photographic angle deprives the female athletes of their sports ability, hard-won professionalism and physically more masculine appearance, meanwhile emphasis and amplify their feminity, sex appeal and reproductive capability. Because the former characteristics may contradict the ideology and the expectations of the readers[13]. In the encoding and communication of the male gaze, female athletes' images are transformed into objects and commodities, in order to exchange values which is usually in the form of attention in news media. And with the help of ideology and consumerism, the images of female athletes is possessed by the male audiences.

\subsection{Inferior and invisibility in the frame}

The word position is frequently associated with status, powers and authority. When people take photos in formal occasions, they always invite the persons with highest status to be in the central position. Audiences are able to recognize and justify the status easily from the position in photography. So the edition of position of athletes reveals the cognition and subconsciousness of the press.

Figure 5 shows all the athletes of the Chinese table tennis team in the Tokyo Olympic Games. The male athletes are in the upper position of the picture and the

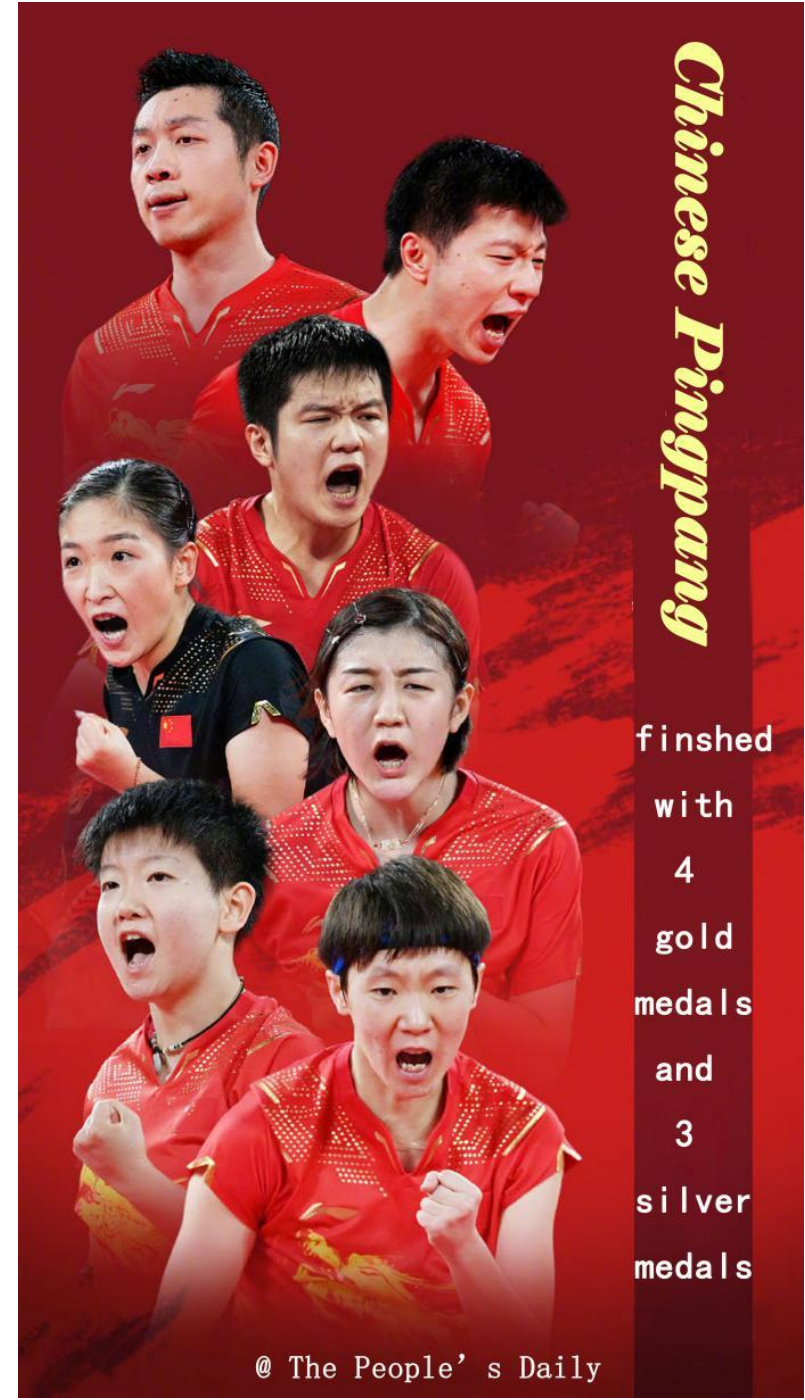

Figure 5 the Chinese table tennis team in the Tokyo Olympic Games by the People's Daily

female athletes are in the below position. In the other eight photos from the same Weibo but are not displayed in this article, the photos of three male athletes are in front of the four female athletes.

The distinction between up and down, forth and back are attached of great importance, particularly in China, as they imply a kind of comparison and rank of status, powers and authority. However, comparison and rank mostly depend on logic, the arrangement in figure 5 does not. If the photos were positioned according to logic, the women's team would be in the forth as they won the champions of both the single and team competitions a few days before the men's team, and the two teams won the same amount of medals. In fact the females are placed in the back because ideology of patriarchy overwhelms logic. In the male gaze, females were always allocated appurtenant and inferior status, and marginal position of the frame[14,15] .

Similarly, in another Weibo (figure 6), athletes also give way to male athletes. Figure 6 is a collection of 
athletes of different ages in and out of China, female athletes also give way to male athletes. Figure 6 is a collection of athletes of different ages in and out of China in the Tokyo Olympic Games, and the arrangement is based on age. The selection of representative athletes is quite meaningful. Picture 1 is Quan Hongchan, the youngest gold medal winner of Chinese team. Picture 2 is Yang Qian, the first champion of the Chinese team. Picture 7 is Oksana Aleksandrovna Chusovitina from Uzbekistan who has taken part in the Olympic Games for most times. Picture 9 is the eldest athlete in the Tokyo Olympic Games, Ni Xialian of Luxembourg. These female athletes are unique in their

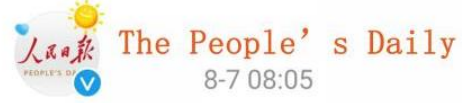

【You just live now! \#the 01ympic athletes born from after 2005 to after 1960\# tell you: people of different ages can beequally wonderful】 14 years old Quan Hongchan got full marks for three times and became famous by a jump, Yang Qian, 21, shot down the first gold and won in a shot, Su Bingtian, 31, made history in 9.83 seconds;Eight-time 0lympian Chusovitina, 46 , is already a victory standing on the field...\#The 01ympics will end tomorrow\#This summer, they tell you, \#Anyone who wants to play is in the year to play!\#
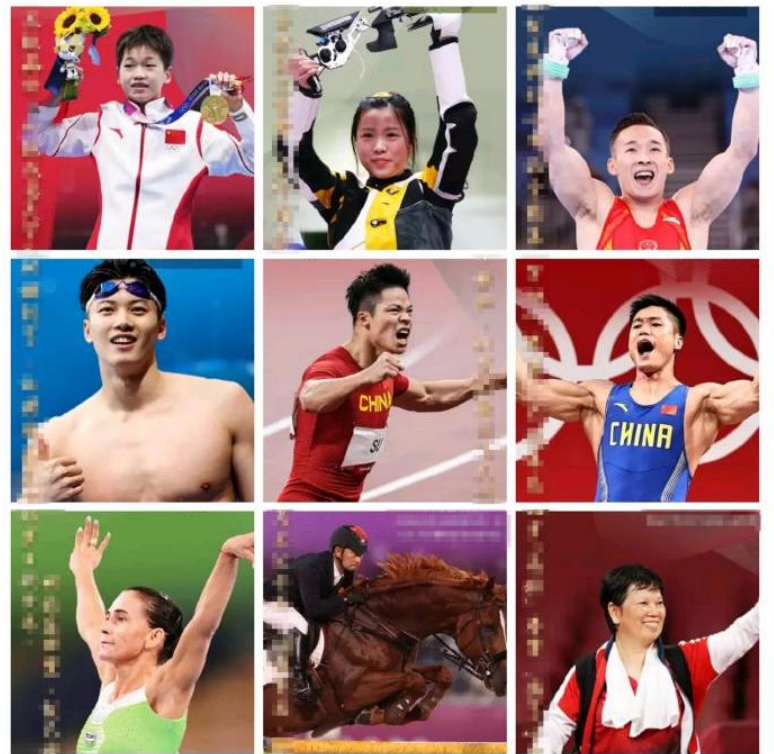

Figure 6 a collection of athletes of different ages by the People's Daily (The writing is: 【You just live now! \#the

Olympic athletes born from after 2005 to after 1960\#

tell you: people of different ages can be equally

wonderful 】14 years old Quan Hongchan got full marks

for three times and became famous by a jump, Yang

Qian, 21, shot down the first gold and won in a shot, Su Bingtian, 31, made history in 9.83 seconds; Eight-time Olympian Chusovitina, 46 , is already a victory standing on the field...\#The Olympics will end tomorrow\# This summer, they tell you, \#Anyone who wants to play is in the year to play!\#) labels and indispensable. However, some male athletes in this Weibo are not that irreplaceable especially in picture 3 and 4, though they are encouraging. There are a lot of female athletes of similar age and same course of hard struggle in the Chinese team.

A non-negligible fact is that in the Chinese team of Tokyo Olympic Games, 298 female athletes won 25 champions while 133 male athletes won 16 champions. Thus there can and should be more female athletes in the collection, but actually less females than males were selected by the press. If the press has choices among males and females, they will tend to pick up males and only to pick up females when there are no other choices. Females are often invisible and forgotten when they stand in the same field with males. It is always the males who are empowered to represent the field.

\section{CONCLUSION}

News images play essential roles in communicating information and constructing social consciousness, and they are also reflection to the ideology of the rule class. This article discussed the ways how the authoritative press displays and constructs the images of female athletes in the news reports on the Tokyo Olympic Games from the perspective of the male gaze.

Generally speaking, news reports in Weibo construct the female athletes' images of obedient, ornamental and inferior, while highlight the males' power, possession of women and dominance, through the facial expression, posture, clothing, viewing angle and position in the frame. These manifestations promote viewers' satisfaction of control, possession of and superior to women. However, it has to be clarified that some phenomena stated above do not only happen in the Chinese context, and are not mainly resulted from Chinese administrators. For example, the request of clothing of athletes is proposed by the organizing committee of Olympic Games and is the consensus of many international competitions. Nevertheless, their communication motivated by the press and media is the key to promote their influence and shape people's cognition as well as attitude, and the influence is continually amplified through the network of social media.

The male gaze in Chinese news images reveals a kind of contradictory condition of China mainstream ideology. In the thousands years of feudal society, China was governed by Confucianism which advocated women were appendages of men and even should not appear outside their home. Not until the modern times did the mind of equality between genders was introduced to China. Although gender equality and women empowerment are core concepts of socialism with Chinese characteristics, patriarchism combined by the tradition of Confucianism and impact of western 
consumerism is still active in China. The male gaze in news reports on the Tokyo Olympic Games is merely the epitome of the whole China. Hence, the media praises the achievement of female athletes (as a symbol of the great China) on the one hand and guarantees men's status in front of women on the other hand.

Fortunately, with the increasing economic status and educational level as well as broadening horizon, more and more females realize the male gaze and inequality upon themselves and attempt to improve the situation. Meanwhile, the Chinese government emphasized protecting the rights and power of women again in the recent policy. We except that the male gaze in news reports will be gradually eliminated by the amendment on ideology and practice of journalistic professionalism in China. The male gaze in news images and other fields still needs constant concern in the future.

\section{REFERENCES}

[1]Mulvey, L. (1989). Visual pleasure and narrative cinema. In Visual and other pleasures (pp. 14-26). Springer. p19.

[2]Pang, L. (2007). The distorting mirror: Visual modernity in China. University of Hawaii Press.

[3]Sontag, S. (2001). On photography (Vol. 48). Macmillan.

[4]Huggins, M. (2008). The sporting gaze: Towards a visual turn in sports history-documenting art and sport. Journal of Sport History, 311-329.

[5]Cummins, R. G., Ortiz, M., \& Rankine, A. (2019). "Elevator eyes" in sports broadcasting: Visual objectification of male and female sports reporters. Communication \& Sport, 7(6), 789-810.

[6]Merrill, K., Bryant, A., Dolan, E., \& Chang, S. (2015). The male gaze and online sports punditry: Reactions to the Ines Sainz controversy on the sports blogosphere. Journal of Sport and Social Issues, 39(1), 40-60.

[7]Evans, B. (2006). 'I'd feel ashamed': Girls' bodies and sports participation. Gender, place \& culture, 13(5), 547-561.

[8]Gieseler, C. (2014). Derby drag: Parodying sexualities in the sport of roller derby. Sexualities, 17(5-6), 758-776.

[9]Gurung, R. A., \& Chrouser, C. J. (2007). Predicting objectification: Do provocative clothing and observer characteristics matter?. Sex roles, 57(1), 91-99.

[10]Mulvey, L. (1989). Visual pleasure and narrative cinema. In Visual and other pleasures (pp. 14-26). Springer. P21.

[11]Pang, L. (2007). The distorting mirror: Visual modernity in China. University of Hawaii Press. p74.

[12]Doane, M. A. (1988). Masquerade reconsidered: Further thoughts on the female spectator. Discourse, 11(1), 42-54. p44-45.

[13]Brandt, M., \& Carstens, A. (2005). The discourse of the male gaze: a critical analysis of the feature section'The beauty of sport'in SA Sports Illustrated. Southern African Linguistics and Applied Language Studies, 23(3), 233-243.

[14]Mincheva, D., \& Hooman, N. (2020). Between the Averted Gaze and the Male Gaze: Women in Farhadi's Films as Tentative Harbingers of Cinematic Islamic Feminism. International Journal of the Image, 11(2).

[15]Verma, K. D. (2000). The Indian imagination: critical essays on Indian writing in English. Springer. 